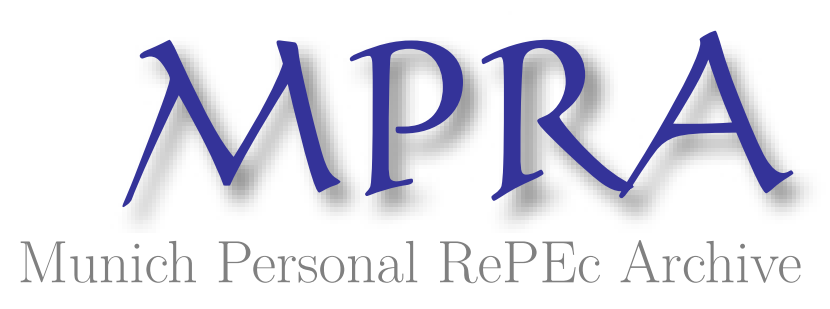

\title{
The asymmetric housing wealth effect on childbirth
}

Iwata, Shinichiro and Naoi, Michio

1 July 2015

Online at https://mpra.ub.uni-muenchen.de/65360/

MPRA Paper No. 65360, posted 01 Jul 2015 08:34 UTC 


\title{
The asymmetric housing wealth effect on childbirth Shinichiro Iwata
}

Faculty of Economics, University of Toyama

Michio Naoi

Faculty of Economics, Keio University

July 1, 2015

\begin{abstract}
The literature has shown that an increase in housing wealth, driven by unexpected shocks to house prices, exerts a positive effect on the birthrates of homeowners. According to canonical models, a decrease in housing wealth has a symmetric negative impact on the fertility behavior of households. That is, housing gains and losses of the same size should have identical quantitative effects on fertility. In comparison, prospect theory suggests that people care more about housing losses than equivalent gains, leading to an asymmetric effect of housing wealth on the fertility decision. In our model, we weight the utility from childbirth by the utility from the price of housing, where the reference level is the house price in previous years. The theoretical model suggests that the probability of childbirth is kinked at a reference level of housing wealth and the wealth effects are discontinuously larger below this kink than above it. We test this theoretical prediction using longitudinal data on Japanese households. Consistent with this theoretical prediction, our empirical results show that the fertility responses of homeowners, as measured by the birth hazard rate, are substantially larger when housing wealth is below its reference level than when it is above its reference level.
\end{abstract}

Key words: childbirth; housing price; wealth; homeownership; reference-dependent preferences; loss aversion 


\section{Introduction}

Owner-occupied housing is the most significant form of wealth holding for both young and middle-aged households in Japan. ${ }^{1}$ Using microdata from the Nikkei Radar (1987-99), which covers households in the Tokyo metropolitan area, Iwaisako (2009) demonstrated that housing wealth accounts for approximately 90 percent of the total wealth of homeowners in their $20 \mathrm{~s}$, and approximately 80 percent of those in their 30s and 40s. Nonetheless, housing wealth fluctuates markedly because of variations in house prices. Figure 1 depicts the Japan Real Estate Institute (JREI) Home Price Index, which is based on the price changes for repeat sales of second-hand condominium properties in the Tokyo metropolitan area. ${ }^{2}$ As shown, after a significant decline in the early 2000s, house values reversed the downward trend in 2005 and reached a peak in October 2007. Housing prices then fell sharply in 2008 and 2009, possibly because of the subprime mortgage crisis. While house values recovered somewhat in 2010, they fell again in 2011.

A voluminous literature has investigated how house price fluctuations affect household consumption decisions. In a pioneering study, Case et al. (2005) argued that the housing wealth effect on consumption has become increasingly important, as institutional innovations have made it simpler to extract cash from housing equity. They hypothesized, and were duly supported by empirical results, that exogenous changes in house prices are associated with changes in the available housing equity, thereby changing consumption. More recently, Lovenheim and Mumford (2013) and Dettling and Kearney (2014) have applied the housing wealth effect to the childbearing choices of households.Using the same logic, they hypothesized that changes in home value imply changes in wealth for current homeowners, and that these changes could consequently affect child bearing decisions. Their empirical results indeed suggested that children are normal goods and that an increase in house prices tended to encourage child bearing among homeowners.

In general, household fertility decisions are an important issue in Japan because the total

\footnotetext{
${ }^{1}$ According to the 2008 Housing and Land Survey, the homeownership rate of Japanese aged 25-29 years was 11.5 percent, while that of those in their $30 \mathrm{~s}$ and $40 \mathrm{~s}$ was 38.8 percent and 62.2 percent, respectively.

${ }^{2}$ The JREI Home Price Indices are available at http://www.reinet.or.jp/en/ (accessed June 12, 2015).
} 
fertility rate was at its lowest level of just 1.26 in 2005. Since then, the total fertility rate has risen slightly, down 0.01 percentage points from the previous year to 1.42 in 2014 . A recent article has sounded the alarm that the total fertility rate is headed for a long-term decline as second-generation baby boomers, born between 1971 and 1974, pass their peak childbearing years. ${ }^{3}$ Examining the purported link between changes in housing wealth and household fertility decisions could then inform this issue. However, unlike Lovenheim and Mumford (2013) and Dettling and Kearney (2014), we shed light on an asymmetry in the response to unanticipated housing wealth gains and losses. If we consider the housing wealth effect on childbirth only through the budget constraint, as in Lovenheim and Mumford (2013) and Dettling and Kearney (2014), we cannot derive this asymmetric effect. We thus examine the impact through a different channel by applying prospect theory as developed by Kahneman and Tversky (1979). This theory suggests that households care more about wealth losses than equivalent gains through the value function. In fact, the empirical results in Genesove and Mayer (2001) demonstrated that homeowners with a potential loss behave differently when compared with those with an equivalent-sized prospective gain. In our model, the utility from childbirth is weighted by the utility from the change in house prices, where the reference level is based on the house price in previous years. The theoretical model then suggests that the probability of childbirth is kinked at a reference level of housing wealth and that the wealth effects are then discontinuously larger below the kink than above it.

We test this theoretical prediction using longitudinal data on Japanese households collected by Keio University. The Keio Household Panel Survey (KHPS) is a nationally representative, large-scale survey that commenced in 2004 with an initial sample of approximately 4,000 households. We use eight waves of the KHPS from 2004 to 2011. As shown in Figure 1, this period appears to be ideal for examining the supposed asymmetric housing wealth effect because the housing market has experienced both price increases and price decreases. These variations in housing wealth are captured by the relative change in self-reported home values, where selfreported home values in previous years serves as the reference level. We measure childbearing

\footnotetext{
${ }^{3}$ Bracing for demographic change: Japan's fertility rate headed for long-term decline. Nikkei Asian Review, June 6, 2015. http://asia.nikkei.com/Politics-Economy/Economy/Japan-s-fertility-rate-headed-for-longterm-decline (accessed June 12, 2015).
} 
choices using the birth hazard rate and estimate proportional hazard models to understand the relationship between changes in housing wealth and family formation behavior. Our empirical results suggest that, consistent with our theoretical prediction, the fertility responses of homeowners are substantially larger when housing wealth is below its reference level than above. Using our empirical results, we then simulate the effect of a one million yen change in house values on the hazard rate. Our estimates indicate that a one million yen decrease in house values decreases the hazard rate of childbirth by approximately 10.9 percent, whereas a one million yen increase in house values leads to an increase in the childbirth hazard rate by a mere 1.0 percent. This suggests that encouraging childbirth through boosting housing markets will entail a different magnitude of impact, depending on housing price gains and losses.

\section{Literature review}

\subsection{The effect of housing wealth on consumption}

Case et al. (2005) used two panels of cross-sectional time series data: one for developed countries measuring aggregate consumption and aggregate housing wealth; and the other for US states measuring aggregate retail sales as a proxy variable for aggregate consumption and the aggregate value of owner-occupied housing. Although the impact was rather small, the empirical results demonstrated that changes in housing prices have a significantly positive impact on household consumption in the US and other developed countries. Subsequently, Case et al. (2013) extended the panel of US states used in their earlier study, by incorporating substantial periods of declines in housing prices. As a result, they identified the statistically significant and rather large effect of housing wealth on consumption spending. Campbell and Cocco (2007) used household-level data from the UK family expenditure survey to estimate the response of consumption to house

prices. Their benchmark model suggested that the elasticity of consumption to house prices is indeed elastic. Paiella (2009) provides a detailed review of this literature.

Elsewhere, Genesove and Mayer (2001) applied the prospect theory developed by Kahneman and Tversky (1979) and Tversky and Kahneman (1991) to the housing market. After introducing their analysis with an account of several sellers who were reluctant to realize a loss on their 
houses, they hypothesized that a seller with a potential loss would be expected to set a higher price and face a lower hazard rate of sale than a seller with an equivalent-sized prospective gain. Indeed, their empirical results, using data from the Boston condominium market, indicated that sellers behave as predicted by the prospect theory. Motivated by this analysis, Case et al. (2013) hypothesized that the painful regrets associated with decreases in home values exert stronger psychological consequences than does the pleasant elation associated with increases in home values, such that homeowners behave asymmetrically as to the gains and losses in housing wealth. The empirical results suggested that an increase in housing wealth has a positive effect on household consumption, while a decline in housing wealth has a negative and somewhat larger effect on consumption, both being consistent with the prospect theory.

Using household-level panel data from the US, Engelhardt (1996) also suggested that savings display significant asymmetry in response to unanticipated gains and losses from housing. That is, homeowners experiencing a housing capital gain do not alter savings behavior, while those experiencing a loss tend to increase savings. Likewise, Disney et al. (2010), using UK household panel data along with county-level house price data, demonstrated that households experiencing an unanticipated loss exhibit a larger reaction in savings than those experiencing an unanticipated gain. However, these differences were found to be not statistically significant.

\subsection{The effect of housing wealth on childbirth}

Lovenheim and Mumford (2013) and Dettling and Kearney (2014) argued that house price movements are appropriate for examining how increases in individual income affect fertility because changes in house prices do not affect the cost of parental time to raise children in the same way that changes in market wages do. An increase in the market wage implies an increase in the value of time spent on labor; thus, the substitution effect reduces fertility (Becker 1965). An increase in housing prices also involves a negative substitution effect on the demand for children, especially for prospective homeowners who would purchase a house with the addition of a child, when the association between children and housing is a complement. However, as discussed, rising home values imply a boost in wealth for current homeowners. Consequently, they could afford to have a child when children are considered normal goods (the wealth effect). 
Even though homeowners do not intend to resell their housing, they can use the increase in equity to fund their childbearing goals (the equity extraction effect).

Lovenheim and Mumford (2013) also noted that house price movements are valid because they can be used to generate exogenous shocks to household wealth, which overcomes the endogeneity between wealth accumulation and childbirth decisions. Using US individual-level data (1985-2007), they estimated linear probability models for families giving birth in a given year as a function of two- and four-year changes in self-reported home values. The empirical results demonstrated that a $\$ 100,000$ increase in an individual's real housing wealth among homeowners was associated with a 16.4 percent increase in the probability of having a child. By comparison, among renters, Metropolitan Statistical Area (MSA)-level housing price growth had no significant effect on current fertility. Because the positive effect of home price changes on childbirth is only observed for homeowners, these tend to capture the hypothesized wealth effect.

Although Lovenheim and Mumford (2013) considered that house price movements are exogenous, potential endogeneity issues remain. For example, households that plan to have children may purchase homes in good neighborhoods, therefore self-selecting into locations that are more likely to experience high housing price growth in the future. Such selection mechanisms bias upwards conventional estimates of the effect of house price growth on fertility. To address this possibility, Dettling and Kearney (2014) used MSA-level housing supply elasticity as an instrumental variable (IV) and estimated IV regression of MSA-level fertility rates on MSA-level house prices during the 1997-2006 housing boom period. Their IV estimates demonstrated that short-term (one-year) increases in house prices led to a decline in births in places where the homeownership rate was relatively low. However, this decline was outweighed by the increase in births where the homeownership rate was relatively high. That is to say, similarly to Lovenheim and Mumford (2013), they found fertility rates for homeowners were positively associated with short-term increases in house prices. In sum, at the mean US home ownership rate in their sample period, the net effect of a $\$ 10,000$ increase in house prices produced a 0.8 percent increase in fertility rates. They also confirmed the findings of previous analysis using aggregate-level data with individual-level Current Population Survey data. At this stage, they considered MSA-level 
house prices conditional on MSA fixed effects to control for endogenous sorting into higher- or lower-priced MSAs.

These estimates appear to predict that a housing market decline may have a symmetric negative impact on fertility. If true, it may help us to understand whether the severe price declines in the housing market following the US subprime mortgage crisis is one of the reasons for the fairly sharp decline in the US birth rate. To examine this hypothesis, Lovenheim and Mumford (2013) used the 16.8 percent of the subsample that experienced price declines. Although they found some evidence that the response was not symmetric, they also found that the effect of falls in home values was not statistically different from zero. This suggests that fertility decisions are less likely to respond to housing market variation during a period of house price falls. Lovenheim and Mumford (2013), however, suggested that more work examining the effect of the housing bust on fertility was needed in the future when data from the period of the housing bust became available. On the other hand, Dettling and Kearney (2014) used data from the housing bust period of 1990-96, and conducted a similar exercise. The empirical results from this period are similar to the housing boom period, supporting a symmetric negative impact. ${ }^{4}$ They also confirmed similar results during the recent housing bust period of 2007-10, even though only individual-level data were used because MSA-level fertility rates were not available at the time.

In sum, Dettling and Kearney (2014) suggested that fertility responses tend to be symmetric irrespective of the rise or fall of house prices, whereas Lovenheim and Mumford (2013) suggested that fertility is more likely to respond when house prices increase than decline. However, both these results are largely inconsistent with prospect theory, which suggests that households care more about wealth losses than equivalent gains.

\section{The theory of childbirth and housing wealth}

Let us define $B_{t}$ as a parameter indicating the propensity to undergo a birth at time $t$, which is endogenously selected by families dwelling in owner-occupied housing. If families do not have a birth, then $B_{t}=0$, whereas if they do, then $B_{t}=1$. We treat $B_{t}$ as a continuous variable

\footnotetext{
${ }^{4}$ However, they argued that the impact appeared to be symmetric because the sign of the coefficients was similar in both the housing bust and housing boom periods. Importantly, they did not consider the magnitude of the coefficients.
} 
that ranges from zero to one, because it allows us to differentiate the objective function, as shown below. Therefore, $B_{t}$ represents the probability of childbirth in our context. Let us define $U\left(B_{t}\right)$ as the utility from expecting to have a child and $C\left(B_{t}\right)$ as the cost function. Assume that $U^{\prime}\left(B_{t}\right)>0, U^{\prime \prime}\left(B_{t}\right)<0, C^{\prime}\left(B_{t}\right)>0$, and $C^{\prime \prime}\left(B_{t}\right)=0$. The household surplus from having a child can then be written as $U\left(B_{t}\right)-C\left(B_{t}\right)$. To introduce the impact of housing wealth on utility, assume that the utility function $U\left(B_{t}\right)$ is weighted by a value function that depends on current housing wealth, $W_{t}$. In this analysis, we assume $W_{t}$ is exogenous for families. The value function captures that the behavior of family members is affected by the estimated value of their housing. We define the house price in the prior year $W_{t-1}$ as the reference wealth level. To apply the theory of reference-dependent preferences, the optimal level of $B_{t}$ is then chosen by maximizing the following modified surplus functions:

$$
\begin{array}{lll}
U\left(B_{t}\right) \Phi\left(W_{t}\right)-C\left(B_{t}\right) & \text { if } & W_{t} \geq W_{t-1} \\
U\left(B_{t}\right) \Psi\left(W_{t}\right)-C\left(B_{t}\right) & \text { if } \quad & W_{t} \leq W_{t-1}
\end{array}
$$

where $\Phi\left(W_{t}\right)$ and $\Psi\left(W_{t}\right)$ represent the value functions. The value functions are assumed to follow diminishing marginal utility over wealth. That is, $\Phi^{\prime}\left(W_{t}\right)>0, \Phi^{\prime \prime}\left(W_{t}\right)<0, \Psi^{\prime}\left(W_{t}\right)>0$, and $\Psi^{\prime \prime}\left(W_{t}\right)<0$.

Assume (A1) $\Phi\left(W_{t-1}\right)=\Psi\left(W_{t-1}\right)$. This assumption ensures that the value functions take the same value at the reference point. Assume also that (A2) $\Phi^{\prime}\left(W_{t-1}\right)<\Psi^{\prime}\left(W_{t-1}\right)$. This assumption reflects that families are loss averse: that is, they are more sensitive to losses than gains, resulting in a greater marginal utility change for losses (Tversky and Kahneman 1991).

The first-order condition for the above problems is:

$$
\begin{array}{lll}
U^{\prime}\left(B_{t}\right) \Phi\left(W_{t}\right)-C^{\prime}\left(B_{t}\right) & \text { if } & W_{t} \geq W_{t-1} \\
U^{\prime}\left(B_{t}\right) \Psi\left(W_{t}\right)-C^{\prime}\left(B_{t}\right) & \text { if } & W \leq W_{t-1}
\end{array}
$$

Let us denote $B_{t}^{*}$ as the optimal level at $W_{t}=W_{t-1}$. Differentiating the first-order condition with respect to housing wealth at $W_{t}=W_{t-1}$ can be written as:

$$
\left.\frac{d B_{t}^{*}}{d W_{t}}\right|_{W_{t}=W_{t-1}}= \begin{cases}-\frac{U^{\prime}\left(B_{t}^{*}\right)}{U^{\prime \prime}\left(B_{t}^{*}\right)} \frac{\Phi^{\prime}\left(W_{t-1}\right)}{\Phi\left(W_{t-1}\right)}>0 \quad \text { if } \quad W_{t} \geq W_{t-1}, \\ -\frac{U^{\prime}\left(B_{t}^{*}\right)}{U^{\prime \prime}\left(B_{t}^{*}\right)} \frac{\Psi^{\prime}\left(W_{t-1}\right)}{\Psi\left(W_{t-1}\right)}>0 \quad \text { if } \quad W \leq W_{t-1} .\end{cases}
$$


Because $\Phi^{\prime}\left(W_{t-1}\right) / \Phi\left(W_{t-1}\right)<\Psi^{\prime}\left(W_{t-1}\right) / \Psi\left(W_{t-1}\right)$ by assumptions (A1) and (A2), equation (1) demonstrates that the optimal propensity to have a child is kinked at the reference housing wealth and that the marginal propensity with respect to an exogenous increase in housing wealth is discontinuously higher below the kink than above it. This suggests a negative effect on fertility because the decline in house prices from the reference point is more pronounced than the positive effect on fertility, as derived from an unexpected rise in house prices.

\section{Empirical analysis}

\subsection{Data and variables}

Our empirical analysis draws on the Keio Household Panel Survey (KHPS) to examine the relationship between housing wealth and the fertility decisions of homeowners. The KHPS, sponsored by the Japan Society for the Promotion of Science (JSPS), is a nationally representative, large-scale longitudinal survey of Japanese households that commenced in 2004 with an initial sample of approximately 4,000 households. In 2007, a random refreshment sample of approximately 1,400 new respondents addressed panel attrition. In the following analysis, we use eight waves of the KHPS from 2004 to 2011. The KHPS is particularly suited to addressing the research questions in this paper because it contains detailed information on household demographic events, including childbirth, the tenure mode of housing and housing wealth, and includes a rich set of family background characteristics.

In the following analysis, a dichotomous variable indicating childbirth represents the event of interest. This variable takes a value of one if the respondent family had a new baby in the last 12 months, and zero otherwise. Duration is defined as follows: 1) years since marriage for those without any child; 2) years since last childbirth for those having at least one existing child.

The KHPS also provides information on the value of the home if it is owned. ${ }^{5}$ Similar to Lovenheim and Mumford (2013), our housing wealth measure is constructed based on selfreported information in the survey ("How much do you think the house and lot would sell for on today's market?"). One could be skeptical about the use of self-reported house values as

\footnotetext{
${ }^{5}$ There are no publicly available data for housing prices in Japan, except the JREI Home Price Indices, which are geographically limited to the Tokyo metropolitan area.
} 
a proxy for market values. The owner's valuation can be inaccurate and include a systematic bias toward optimistic evaluation. In fact, Kiel and Zabel (1999) showed that the average owner overstates their house value by $5.1 \%$. Using self-reported house values can pose a serious problem in our application if the measurement errors in an owner's valuation are correlated with birth behavior. This can be possible if there are some omitted variables in our model that are also correlated with self-reported house values. Again, however, Kiel and Zabel (1999) showed that valuation errors are not correlated with owner's individual characteristics as well as the house and neighborhood attributes. Furthermore, because our housing wealth measure is the change in self-reported values, problems arising from systematic overvaluation can be largely mitigated. In fact, several previous studies have shown that owners' valuations result in accurate estimates of house price indices (Kiel and Zabel 1999; Lovenheim 2011). Overall, we believe that using selfreported values will represent only a minor problem in our specific application. In the following analysis, we assume that the reference wealth level is defined as the status quo, that is, the self-reported value in the previous year, $W_{t-1}$. This is a standard assumption in the literature where the reference state corresponds to the decision maker's current endowment (Tversky and Kahneman 1991; Dettling and Kearney 2013).

In addition to these variables, we gather a number of important economic and demographic characteristics from the KHPS. These include a dummy variable indicating the number of existing children prior to the new childbirth in question, the female respondent's age and its square, the level of completed education (high school, technical college/vocational school, two-year college, and four-year college or higher), employment status (not employed, employed part-time, and employed full-time), and male respondent's labor earnings. ${ }^{6}$ We also control for region, city size, and survey year using dummy variables in each of our estimations. All monetary variables are converted to 2005 prices using the Consumer Price Index.

The original survey includes 4,005 households in 2004 (wave 1) with 1,419 households added in 2007, resulting in 5,424 unique households. Of these households, 870 households participated in the survey only once (i.e., dropped out in the second wave). As we use lagged information

\footnotetext{
${ }^{6}$ Women's employment careers are likely to be interrupted by childbirth and infant care, leading to a typical reverse-causality problem. Therefore, for the employment status, we specify our dummy variables according to the status prior to the childbirth.
} 
(i.e., household and housing characteristics from the previous wave) in our empirical analysis, we exclude these households, resulting in 4,554 unique households.

As our purpose is to identify the impact of self-reported house values on childbirth, we restricted our sample to homeowners who did not move during the survey period. For mover households, changes in self-reported house values cannot be interpreted as real house price changes. Furthermore, house values can increase through additions and/or repairs, even when market prices are stable. We therefore exclude homeowners that made any additions and/or repairs to their home from our sample. This reduced our sample further to 3,407 unique households.

The sample was further restricted to households with a married woman of childbearing age, i.e., a female respondent aged between 20 and 50 years. This reduced the number of unique households further to 1,250 . This reduction is substantial because the KHPS covers both singleperson (unmarried) households and the elderly. Finally, restricting the sample to those where all necessary information was available further reduced the number of unique households to 932 . Taking each household-year pair as a unit of observation, our estimation is based on a total of 2,893 observations.

Table 1 provides selected descriptive statistics for our variables. The childbirth dummy has an average value of approximately 0.02 , indicating we have a total of 60 births in our observations during the sample period. One reason for this low value may be that the average age of female respondents is approximately 41 years, as reported in Table 1 , and they already have approximately two children on average (not shown). The mean self-reported home values is approximately 23.1 million yen (not shown). On average, home values decreased by about 1.5 million yen during the sample period.

Figure 2 illustrates the average self-reported home values over time. As shown, the average house values increased from 2006 to 2007. Afterwards, house values steadily declined until 2010 where they remained through to 2011. The average self-reported home values in the Tokyo metropolitan area also display the same tendency. However, from 2010 to 2011, average selfreported home values increased in the Tokyo metropolitan area.

Table 2 highlights the differences in variables for respondents who responded depending 
on whether they had experienced housing price gains or losses. For the sake of simplicity, we categorize these into housing wealth gainers and losers, where the former also includes those who reported the same house value as the previous year (524 observations). ${ }^{7}$ Approximately half of the observations showed price increases. For these, home values increased approximately 4.3 million yen on average. Excluding households that reported $W_{t}=W_{t-1}$, the average price appreciation was 6.6 million yen. The remaining half of the observations experienced price declines. For these, home values decreased approximately 7.6 million yen on average. In sum, our dataset appears to cover well both housing wealth gainers and losers.

\subsection{Econometric model}

Because our data are in the form of panel data, we analyze decisions on childbirth within the framework of a duration model. We thus modify the notation of our theoretical model, such that instead of $B_{t}$, we use the birth hazard rate $B(t)$. The birth hazard rate is the probability that childbirth is realized, given that the birth interval lasts at least until $t$. Our benchmark proportional hazard model can be written as:

$B(t)=B_{0}(t ; Y, M) \exp \left\{\beta_{G} d_{\left[W_{t} \geq W_{t-1}\right]}\left(\frac{W_{t}-W_{t-1}}{W_{t-1}}\right)+\beta_{L} d_{\left[W_{t}<W_{t-1}\right]}\left(\frac{W_{t}-W_{t-1}}{W_{t-1}}\right)+\delta X(t)\right\}$,

where $B_{0}$ is an unknown baseline hazard at $t$. In order to control for underlying heterogeneity in birth behavior, we stratify the baseline hazard by the year of birth $(Y)$ and the year in which households moved into the current residence $(M) .{ }^{8}$ This allows us to control for cohort effects, as suggested by Hashimoto and Kondo (2012), and the effects of different housing market conditions at the time of home purchase. For the latter, Öst (2012) suggested that institutional factors in the housing market, such as the housing subsidies and tax benefits associated with home purchase, can potentially affect subsequent birth behavior. $X(t)$ is a set of other explanatory variables, and $\delta$ is the corresponding parameter vector. $d_{[A]}$ is an indicator function that takes

\footnotetext{
${ }^{7}$ However, whether we include these households with the housing gainers does not fundamentally change our results. See the discussion in Section 4.4.

${ }^{8}$ In the estimation, we classify female respondents into three groups based on their birth year (born in and before 1959, born between 1960 and 1969, and born in and after 1970) and into six groups based on the year in which the woman moved into her current residence (in and before 1959, between 1960 and 1969, between 1970 and 1979, between 1980 and 1989, between 1990 and 1999, and in and after 2000). As a result, we allow for different baseline hazard functions for 18 subgroups $(3 \times 6)$.
} 
a value of one if the event $A$ is true, and zero otherwise. Therefore, holding all other things constant, the effect of the annual percentage changes in housing wealth on the birth hazard rate can be represented by $\beta_{G}$ if $W_{t} \geq W_{t-1}$, and $\beta_{L}$ if $W_{t}<W_{t-1}$. Our theoretical model predicts that the optimal propensity to have a child is kinked at the reference housing wealth and that the marginal propensity with respect to an exogenous increase in housing wealth is discontinuously higher below the kink than above it. This implies that $\beta_{G}<\beta_{L}$.

\subsection{Empirical results}

As a preliminary step, we begin by considering a simpler model excluding any asymmetric impact of housing wealth on fertility decisions. Specifically, we estimate the model given by equation (2) with the restriction that $\beta_{G}=\beta_{L}$. We estimate the model by applying a standard Cox's proportional hazard model for childbirth. Table 3 presents the empirical results. The results in column [1] show that a short-term increase in house prices is positively associated with the homeowner's probability of giving birth in a given year. This result is consistent with previous findings in the literature. However, Lovenheim and Mumford (2013) and Dettling and Kearney (2014) used data from a housing boom period, while our data include both housing boom and bust periods. The significantly positive sign indicates that during a housing boom (bust) period, an increase (decrease) in house prices leads to a positive (negative) wealth effect on the fertility decisions of homeowners. In addition, we also present regression results using an alternative specification for the housing wealth measure, i.e., annual changes in the level of self-reported house values $\left(W_{t}-W_{t-1}\right)$, in column [2] of Table 3. These results also suggest that short-term increases in house prices are positively associated with the homeowner's probability of giving birth.

In terms of the demographic and family background variables, our results are as follows. Female respondent's age has a significant nonlinear effect on childbirth. The estimated results

show that the probability of giving birth increases through the female respondent's 20s, reaching a maximum at around 30, and then decreasing throughout the respondent's 30s and 40s. The number of existing children is significantly and negatively associated with the probability of have an additional birth (not shown). The education of the female respondent also matters in that 
respondents with a four-year college or postgraduate degree tend to have a significantly lower probability of giving birth. As expected, female employment status is associated with childbirth. Compared with respondents not working, the probability of giving birth is considerably lower for those working part or full time (in year $t-1$ ), although the estimated coefficient is not significant in the case of the latter.

Given these preliminary results, we now test the asymmetric impact of housing wealth on the fertility decision. The results are in columns [3] and [4] of Table 3. The null hypothesis of equal wealth coefficients, $H_{0}: \beta_{G}=\beta_{L}$, is tested against the one-sided alternative $H_{a}: \beta_{G}<\beta_{L}$. From column [3], we find that the estimated coefficient on short-term increases in housing values is significantly positive when $W_{t}<W_{t-1}($ coef. $=2.684)$. In comparison, the estimated coefficient on short-term increases is still positive but considerably smaller and statistically insignificant when $W_{t} \geq W_{t-1}$ (coef. $\left.=0.227\right)$. This is consistent with our theoretical prediction that the fertility responses of homeowners are substantially larger when their housing wealth is below its reference level than when housing wealth is above its reference level. As a result, the null hypothesis of equal wealth coefficients, $H_{0}: \beta_{G}=\beta_{L}$, is strongly rejected. The results in column [4] using annual changes in the level of house values yield qualitatively similar findings.

In order to evaluate the results in column [3] quantitatively, we calculate the predicted effect of a one million yen change in house prices on the birth hazard rate. Given that the average house value in our dataset is 23.1 million yen, a one million yen change translates into a relative house value change of 0.043 , which is close to the mean rate of change given in Table $2(0.042)$. Our coefficient estimate of $\beta_{L}$ suggests that households facing a one million yen decrease in their house values were approximately 10.9 percent less likely to have an additional birth in the

following year $\left(1-e^{-0.043 \times \beta_{L}}=0.109\right)$. Conversely, a one million yen increase in house values corresponds to a mere 1.0 percent increase in the hazard rate $\left(e^{-0.043 \times \beta_{G}}=1.010\right)$.

\subsection{Robustness checks}

The remainder of this section reports the results of additional specifications to assess the robustness of our main findings. We estimate three alternative models in addition to our benchmark model. These results are summarized in Table 4. In column [1], we use house value changes 
in the past two years, $\left(W_{t}-W_{t-2}\right) / W_{t-2}$, as an alternative wealth measure. This enables us to examine longer-term effects of housing wealth changes on childbirth. The estimated results show qualitatively the same pattern as our benchmark results.

As we assume that the reference wealth level coincides with the status quo $\left(W_{t-1}\right)$, any measurement errors in past house values can bias our results. Measurement error in past house values presumably poses a particularly serious problem if current housing wealth is not so different from the reference wealth level (i.e., $W_{t} \approx W_{t-1}$ ). This is because only a small amount of measurement error in the past house values can change whether a particular household has housing wealth above (or below) the reference level. Therefore, in column [2] of Table 4, we exclude households that report the same self-reported house values across adjacent years, i.e., $W_{t}=W_{t-1}$. Because 524 households reported exactly the same house values across adjacent years, this substantially reduces our sample size. The estimated results presented in column [2], however, are qualitatively similar to our benchmark results. The estimated coefficient on housing losses (coef. $=3.112$ ) is somewhat larger than in our benchmark result, but we continue to observe an asymmetric wealth effect. We therefore believe that measurement errors do not pose serious problems in our estimation.

In column [3] of Table 4, we estimate the same model using the sample households that already had at least one child (i.e., second and subsequent births) in order to examine whether homeowners' fertility responses differ for first and subsequent births (Lovenheim and Mumford 2013). The estimated coefficient on housing losses turns out to be larger than in our benchmark result, consistent with previous findings. While fertility responses for first births might be interpreted as changes in the optimal timing of childbirth, those for second and subsequent births may represent changes in the total number of children. Therefore, our results suggest that housing wealth affects not only the timing of childbirth but also the total number of children.

In Table 5 we present several alternative models allowing for more flexible specifications of housing gains/losses. In column [1], we added a dummy variable indicating whether respondents experienced housing gains. Our theoretical model assumes that the value function is continuous at the reference point (assumption A1). Consistent with this assumption, the additional dummy 
variable has a statistically insignificant coefficient estimate for childbirth. In addition, the coefficient estimates for changes in self-reported house values are quantitatively similar to our benchmark results in column [3] of Table 3.

In column [2] of Table 5, we adopt a quadratic specification for both housing gains and losses. This specification is useful for testing whether the asymmetric housing wealth responses in the benchmark results are driven by potential nonlinearity of the effects of the housing gains and losses. The estimated results, however, indicate that the quadratic terms for housing gains and losses are both statistically insignificant, implying that the underlying relationship between housing wealth and fertility may not be (at least quadratically) nonlinear. ${ }^{9}$

Up to now, we have exclusively focused on existing homeowners to evaluate the effects of housing wealth on childbirth. As discussed earlier, a rise in house prices will increase the available resources of homeowners, and may lead to a positive effect on fertility decisions. An increase in house prices, on the other hand, will have the opposite effect on prospective owners (i.e., renters), as this will require a larger deposit for future home purchases and reduce the available resources for these households. In order to examine the effects of housing price changes on renters, we derive year-on-year changes in regional house prices by regressing the homeowner's self-reported values on region-city size fixed effects. ${ }^{10}$ The estimation results for the house value regression imposing an $\mathrm{AR}(2)$ process are in Table 6. We obtains the predicted house value changes for each region-city size-year combination using these results.

Table 7 provides our estimation results using regional house value changes. The first two columns present the regression results for homeowners. In column [1], although the coefficient estimate is not statistically significant, we can see that changes in regional house values have a positive effect on childbirth. In addition, allowing for an asymmetric effect, as in column [2] of Table 7, we can see that changes in regional house values have a significantly positive coefficient

\footnotetext{
${ }^{9}$ Instead of rate changes in self-reported values, we use absolute change in self-reported values and its square. Although we were unable to stratify the baseline hazard because of a problem with convergence, a quadratic specification fits both housing gains and losses well. Even with this quadratic specification, we still find that the fertility responses are asymmetric in terms of housing gains and losses. That is, housing losses have a larger impact on fertility than do gains of an equivalent size.

${ }^{10}$ KHPS categorizes a respondent's location of residence in eight regions (Hokkaido, Tohoku, Kanto, Chubu, Kinki, Chugoku, Shikoku, and Kyushu) and three city sizes (20 major cities, other smaller cities, and towns/villages). Based on this information, we created dummy variables for every possible combination of regions, city sizes, and survey years, and used them to control for fixed effects in Table 6.
} 
estimate only when regional house values decrease. Overall, the estimated coefficients on housing wealth variables display a qualitatively similar pattern as our benchmark case in columns [1] and [3] of Table 3, implying that our predicted house value changes well capture any regional house price variation. The regression results for renter households are in column [3]. As shown, regional house price changes have a negative, although not statistically significant, impact on renter fertility decisions (Lovenheim and Mumford 2013).

\section{Conclusion}

This paper estimated the responses of homeowner childbirth to changes in housing wealth using recent longitudinal data on Japanese households. The main contribution of our analysis is to highlight the role of reference-dependent preferences, as assumed by prospect theory, in explaining household fertility decisions and their relationship with changes in housing wealth. Using the empirical specifications commonly used in existing studies, we found that the propensity to have a child is positively associated with housing wealth changes. This suggests that a decrease in housing wealth has a symmetric negative impact on fertility decisions. However, our empirical specifications, which allow for a different impact on childbirth depending on gains or losses in housing prices, supported our arguments that the fertility responses of homeowners are substantially larger when housing wealth is below its reference level than when housing wealth is above its reference level. The empirical results demonstrated that homeowners facing a one million yen decrease in house values from the previous year were approximately 10.9 percent less likely to have an additional birth in the next year, while a one million yen increase in house values lead to a mere 1.0 percent greater likelihood of giving birth. This is consistent with the theoretical model of prospect theory that predicts disproportionately higher wealth effects on childbirth when housing prices fall below some reference level. The empirical findings were robust to alternative specifications.

We do not intend to argue against other reasons explaining the evidence presented here. In some countries, the budget constraint of homeowners shifts differently for housing price gains and losses. This could also apply in the Japanese case. Throughout the 1990s and into 
the early 2000s, many Japanese homeowners encountered negative equity because the loss in housing value was substantial. To address this problem, the government revised the tax system in 2004 such that households could deduct capital losses on property held for personal use. Seko and Sumita (2007) focused on the 2004 tax revisions and found that they increased home replacement, especially for households with a large loan-to-value ratio. In our context, the 2004 tax revisions may impact on the budget constraint only when homeowners realize a loss on their house; accordingly, housing wealth has an asymmetric impact on childbirth. However, to capture this impact, the reference wealth level must be the purchase price rather than the price in the previous year, because capital gains and losses are based on the purchase price. To repeat, we use the house price in the prior year as the reference wealth level. Instead, the asymmetric housing wealth effect on childbirth through the value function may be an additional explanation (Genesove and Mayer 2001; Case et al. 2013). In fact, Nakagawa and Saito (2012) have suggested that Japanese people tend to behave as expected by prospect theory using survey data that asked apartment residents in the Tokyo metropolitan area to select their preferred investment plan for mitigating earthquake risk.

It is useful to consider the policy implication of this paper. To increase the fertility rate of homeowners, a government may attempt to raise house values. However, our empirical evidence regarding the asymmetric housing wealth effect indicates that this kind of policy may be valid only when housing prices have a downward trend. That is, policy may not dramatically improve the fertility rates of homeowners during a boom phase, because housing wealth has such a small impact on childbirth during this time.

\section{Acknowledgments}

We would like to thank Mototsugu Fukushige, Hassan Gholipour Fereidouni, Robert Jahoda, and Yuko Nozaki, seminar participants at Gakushuin University, Kanagawa University, and the National Institute of Population and Social Security Research and conference attendees at AsRES, ARSC, ENHR, ERES, and JEA for their valuable comments and suggestions. We are also grateful to the Panel Data Research Center at Keio University for access to its microdata. This research was supported by the JSPS KAKENHI Grant No. 10334707. 


\section{References}

Becker, G. (1965). A theory of the allocation of time, Economic Journal, 75, 493-517.

Campbell, J. Y., and Cocco, J. F. (2007). How do house prices affect consumption? Evidence from micro data. Journal of Monetary Economics, 54, 591-621.

Case, K. E., Quigley, J. M., and Shiller, R. J. (2005). Comparing wealth effects: The stock market versus the housing market. Advances in Macroeconomics, 5, 1-32.

Case, K. E., Quigley, J. M., and Shiller, R. J. (2013). Wealth effects revisited 1975-2012. Critical Finance Review, 2, 101-128.

Dettling, L. J., and Kearney, M.S. (2014). House prices and birth rates: The impact of the real estate market on the decision to have a baby. Journal of Public Economics, 110, 82-100.

Disney, R., Gathergood, J., and Henley, A. (2010). House price shocks, negative equity, and household consumption in the United Kingdom. Journal of the European Economic Association, 8, 1179-1207.

Engelhardt, G. V. (1996). House prices and home owner saving behavior. Regional Science and Urban Economics, 26, 313-336.

Genesove, D., and Mayer, C. (2001). Loss aversion and seller behavior: Evidence from the housing market. Quarterly Journal of Economics, 116, 1233-1260.

Hashimoto, Y., and Kondo, A. (2012). Long-term effects of labor market conditions on family formation for Japanese youth. Journal of the Japanese and International Economies, 26, $1-22$.

Iwaisako, T. (2009). Household portfolios in Japan. Japan and the World Economy, 21, 373382.

Kahneman, D., and Tversky, A. (1979). Prospect theory: An analysis of decision under risk. Econometrica, 47 263-291. 
Kiel, K. A., and Zabel, J. E. (1999). The accuracy of owner-provided house values: The 1978-1991 American Housing Survey. Real Estate Economics 27, 263-298.

Lovenheim, M. F. (2011). The effect of liquid housing wealth on college enrollment. Journal of Labor Economics, 29, 741-771.

Lovenheim, M. F., and Mumford K. J. (2013). Do family wealth shocks affect fertility choices? Evidence from the housing market boom and bust. Review of Economics and Statistics, $95,464-475$

Nakagawa, M., and Saito, M. (2012). Prospect theory and the choice of earthquake resistant apartments. In: Saito, M., and Nakagawa, M. (Eds.) Earthquake Risk Management from the Aspect of Human Behavior: Designing New Social System. Keisoshobo, Tokyo, pp.179-206, in Japanese.

Öst, C. E. (2012). Housing and children: Simultaneous decisions? - A cohort study of young adults' housing and family formation decision. Journal of Population Economics, 25, 349366.

Paiella, M. (2009). The stock market, housing and consumer spending: A survey of the evidence on wealth effects. Journal of Economic Surveys, 23, 947-973.

Seko, M., and Sumita, K. (2007). Effects of government policies on residential mobility in Japan: Income tax deduction system and the rental act. Journal of Housing Economics, $16,167-188$

Tversky, A., and Kahneman, D. (1991). Loss aversion in riskless choice: A reference-dependent model. Quarterly Journal of Economics, 106, 1039-1061. 
Table 1: Summary statistics

\begin{tabular}{lll}
\hline Variable & Mean & Std. Dev. \\
\hline Childbirth $^{\dagger}$ & 0.021 & 0.143 \\
Changes in house value (in 10 million yen) & -0.149 & 1.908 \\
Age (in years) & 41.323 & 5.428 \\
Education ${ }^{\dagger}$ & & \\
High school & 0.455 & 0.498 \\
Technical college/vocational school & 0.073 & 0.260 \\
Two-year college $_{\text {Four-year college or higher }}$ & 0.316 & 0.465 \\
Employment status & \\
Not employed & 0.148 & 0.355 \\
Employed part time & & \\
Employed full time & 0.330 & 0.470 \\
Husband's labor income (in million yen) & 6.450 & 3.190 \\
Observations & 0.355 & 0.479 \\
\hline
\end{tabular}

Notes: ${ }^{\dagger}$ denotes a dummy variable. Changes in house value measured by the difference between $W_{t}$ and $W_{t-1}$. 
Table 2: Changes in house values

\begin{tabular}{llllll}
\hline & & \multicolumn{2}{l}{ Rate $\left(W_{t}-W_{t-1}\right) / W_{t-1}$} & \multicolumn{2}{l}{ Difference $\left(W_{t}-W_{t-1}\right)$} \\
& Observations & Mean & Std. Dev. & Mean & Std. Dev. \\
\hline Full sample & 2,893 & 0.042 & 0.895 & -0.149 & 1.908 \\
Gains $\left(W_{t} \geq W_{t-1}\right)$ & 1,485 & 0.319 & 1.170 & 0.426 & 1.183 \\
Losses $\left(W_{t}<W_{t-1}\right)$ & 1,408 & -0.250 & 0.187 & -0.755 & 2.301 \\
\hline
\end{tabular}


Table 3: Benchmark results for Cox's proportional hazard estimates

\begin{tabular}{|c|c|c|c|c|}
\hline & {$[1]$} & [2] & {$[3]$} & [4] \\
\hline & Rate & Difference & Rate & Difference \\
\hline \multirow[t]{2}{*}{ Changes in house value } & $0.354^{* * *}$ & $0.158^{*}$ & & \\
\hline & $(0.129)$ & $(0.085)$ & & \\
\hline \multirow[t]{2}{*}{ Gains in house value $\left(\beta_{G}\right)$} & & & 0.227 & 0.084 \\
\hline & & & $(0.146)$ & $(0.087)$ \\
\hline \multirow[t]{2}{*}{ Losses in house value $\left(\beta_{L}\right)$} & & & $2.684^{* * *}$ & $0.893^{* * *}$ \\
\hline & & & $(0.713)$ & $(0.287)$ \\
\hline \multirow[t]{2}{*}{ Age } & $2.112^{* * *}$ & $2.361^{* * *}$ & $2.116^{* * *}$ & $2.106^{* * *}$ \\
\hline & $(0.599)$ & $(0.696)$ & $(0.571)$ & $(0.623)$ \\
\hline \multirow[t]{2}{*}{ Age-squared } & $-3.236^{* * *}$ & $-3.648^{* * *}$ & $-3.250^{* * *}$ & $-3.265^{* * *}$ \\
\hline & $(0.895)$ & $(1.052)$ & $(0.852)$ & $(0.943)$ \\
\hline \multicolumn{5}{|l|}{ Education (ref: high school) } \\
\hline \multirow[t]{2}{*}{ Technical college/vocational school } & 0.494 & 0.616 & 0.398 & 0.545 \\
\hline & $(0.494)$ & $(0.468)$ & $(0.476)$ & $(0.428)$ \\
\hline \multirow[t]{2}{*}{ Two-year college } & -0.495 & -0.421 & -0.517 & -0.451 \\
\hline & $(0.334)$ & $(0.324)$ & $(0.328)$ & $(0.318)$ \\
\hline \multirow[t]{2}{*}{ Four-year college or above } & $-1.211^{* * *}$ & $-1.178^{* * *}$ & $-1.263^{* * *}$ & $-1.244^{* * *}$ \\
\hline & $(0.449)$ & $(0.452)$ & $(0.475)$ & $(0.467)$ \\
\hline \multicolumn{5}{|l|}{ Employment status (ref: not employed) } \\
\hline \multirow[t]{2}{*}{ Employed part time } & $-1.200^{* * *}$ & $-1.151^{* * *}$ & $-1.302^{* * *}$ & $-1.213^{* * *}$ \\
\hline & $(0.446)$ & $(0.444)$ & $(0.468)$ & $(0.446)$ \\
\hline \multirow[t]{2}{*}{ Employed full time } & -0.255 & -0.323 & -0.311 & -0.361 \\
\hline & $(0.307)$ & $(0.312)$ & $(0.321)$ & $(0.317)$ \\
\hline \multirow[t]{2}{*}{ Husband's labor income } & -0.050 & -0.046 & -0.046 & -0.044 \\
\hline & $(0.058)$ & $(0.058)$ & $(0.056)$ & $(0.056)$ \\
\hline Wald tests & & & $10.96^{* * *}$ & $6.87^{* * *}$ \\
\hline [p-value $]$ & & & {$[0.000]$} & {$[0.004]$} \\
\hline Log-likelihood & -166.38 & -167.09 & -163.78 & -165.01 \\
\hline Pseudo $R^{2}$ & 0.163 & 0.160 & 0.176 & 0.171 \\
\hline
\end{tabular}

Notes: Number of observations is 2,893. Robust standard errors clustered by household ID are in parentheses. Dummy variables for the number of existing children, region, city size, and survey year are included but estimates are not shown. The baseline hazard is stratified by birth cohort and the year moved into current residence. Age-squared divided by 100 . The null hypothesis of $\beta_{G}=\beta_{L}$ is tested using one-sided Wald tests against the alternative of $\beta_{G}<\beta_{L}$. The test statistics have a chi-squared distribution with one degree of freedom. ${ }^{* *}$, and ${ }^{*}$ indicate significance at the 0.01 and 0.10 levels, respectively. 
Table 4: Robustness checks of Cox's proportional hazard estimates

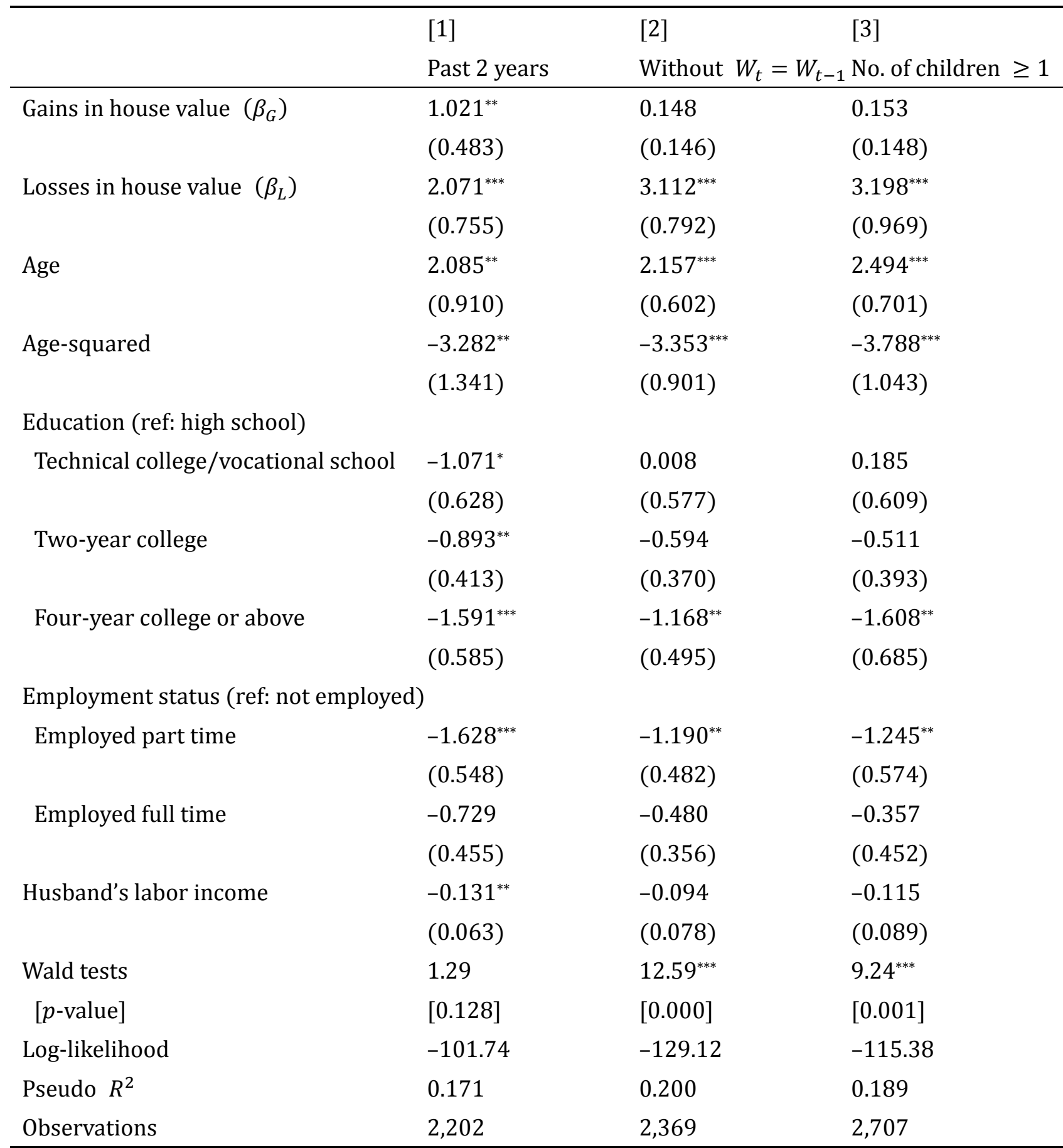

Notes: House value specification is rates. Robust standard errors clustered by household ID are in parentheses. Dummy variables for the number of existing children, region, city size, and survey year are included but results are not shown. In model [1], region dummies are excluded from the model because of a problem with convergence. The baseline hazard is stratified by birth cohort and the year moved into current residence. Age-squared divided by 100. The null hypothesis of $\beta_{G}=\beta_{L}$ is tested using one-sided Wald tests against the alternative of $\beta_{G}<\beta_{L}$. The test statistics have a chi-squared distribution with one degree of freedom. ${ }^{* * *},{ }^{* *}$, and ${ }^{*}$ indicate significance at the $0.01,0.05$, and 0.10 levels, respectively. 
Table 5: Alternative specifications of housing gains/losses of Cox's proportional hazard estimates

\begin{tabular}{|c|c|c|}
\hline & {$[1]$} & {$[2]$} \\
\hline \multirow[t]{2}{*}{ Gains in house value } & $0.260^{*}$ & 0.268 \\
\hline & $(0.150)$ & $(0.538)$ \\
\hline \multirow[t]{2}{*}{ Gains in house value squared } & & -0.005 \\
\hline & & $(0.108)$ \\
\hline \multirow[t]{2}{*}{ Losses in house value } & $3.559^{* * *}$ & 1.149 \\
\hline & $(1.195)$ & $(2.182)$ \\
\hline \multirow[t]{2}{*}{ Losses in house value squared } & & -3.274 \\
\hline & & $(5.001)$ \\
\hline \multirow{2}{*}{ Housing gains dummy $\left(W_{t} \geq W_{t}\right)$} & -0.382 & \\
\hline & $(0.391)$ & \\
\hline \multirow[t]{2}{*}{ Age } & $2.190^{* * *}$ & $2.188^{* * *}$ \\
\hline & $(0.608)$ & $(0.597)$ \\
\hline \multirow[t]{2}{*}{ Age-squared } & $-3.356^{* * *}$ & $-3.350^{* * *}$ \\
\hline & $(0.905)$ & $(0.888)$ \\
\hline \multicolumn{3}{|l|}{ Education (ref: high school) } \\
\hline \multirow[t]{2}{*}{ Technical college/vocational school } & 0.368 & 0.410 \\
\hline & $(0.483)$ & $(0.481)$ \\
\hline \multirow[t]{2}{*}{ Two-year college } & -0.546 & -0.525 \\
\hline & $(0.341)$ & $(0.329)$ \\
\hline \multirow[t]{2}{*}{ Four-year college or above } & $-1.294^{* * *}$ & $-1.266^{* * *}$ \\
\hline & $(0.471)$ & $(0.468)$ \\
\hline \multicolumn{3}{|l|}{ Employment status (ref: not employed) } \\
\hline \multirow[t]{2}{*}{ Employed part time } & $-1.306^{* * *}$ & $-1.292^{* * *}$ \\
\hline & $(0.478)$ & $(0.474)$ \\
\hline \multirow[t]{2}{*}{ Employed full time } & -0.289 & -0.286 \\
\hline & $(0.314)$ & $(0.312)$ \\
\hline \multirow[t]{2}{*}{ Husband's labor income } & -0.047 & -0.048 \\
\hline & $(0.054)$ & $(0.056)$ \\
\hline Wald tests & $7.80^{* * *}$ & $4.77^{* *}$ \\
\hline [p-value $]$ & [0.003] & {$[0.046]$} \\
\hline Log-likelihood & -163.39 & -163.59 \\
\hline Pseudo $R^{2}$ & 0.178 & 0.177 \\
\hline
\end{tabular}

Notes: Number of observations is 2,893. House value specification is rate. Robust standard errors clustered by household ID are in parentheses. Dummy variables for the number of existing children, region, city size, and survey year are included but results are not shown. In model [1], the baseline hazard is stratified by birth cohort and the year moved into current residence. The null hypothesis of $\beta_{G}=\beta_{L}$ is tested using one-sided Wald tests against the alternative of $\beta_{G}<\beta_{L}$. For model [2], the joint hypothesis of equal coefficients on linear and quadratic gains/loss terms is tested. The test statistics have a chi-squared distribution with one/two degrees of freedom. ${ }^{* * *},{ }^{* *}$, and ${ }^{*}$ indicate significance at the $0.01,0.05$, and 0.10 levels, respectively. 
Table 6: AR(2) estimates for self-reported house values

\begin{tabular}{ll}
\hline & House value \\
\hline Self-reported house value $(t-1)$ & 0.068 \\
& $(0.043)$ \\
Self-reported house value $(t-2)$ & $0.108^{* * *}$ \\
& $(0.015)$ \\
Constant & $1.771^{* * *}$ \\
& $(0.209)$ \\
\hline
\end{tabular}

Notes: Number of observations is 4,810. Model is estimated using ArellanoBond dynamic panel GMM estimator. Dummy variables for region-city sizeyear combinations, i.e., region $\times$ city size $\times$ year, are included but results not shown. ${ }^{* * *}$ indicates significance at the 0.01 level. 
Table 7: Cox's proportional hazard estimates using regional average house value changes

\begin{tabular}{|c|c|c|c|}
\hline & {$[1]$} & {$[2]$} & [3] \\
\hline & Homeowners & Homeowners & Renters \\
\hline \multirow[t]{2}{*}{ Changes in house value } & 0.083 & & -1.189 \\
\hline & $(1.046)$ & & $(1.697)$ \\
\hline \multirow[t]{2}{*}{ Gains in house value $\left(\beta_{G}\right)$} & & -3.218 & \\
\hline & & $(2.531)$ & \\
\hline \multirow[t]{2}{*}{ Losses in house value $\left(\beta_{L}\right)$} & & $3.641^{*}$ & \\
\hline & & $(2.169)$ & \\
\hline \multirow[t]{2}{*}{ Age } & 0.498 & $0.721^{* *}$ & 0.466 \\
\hline & $(0.347)$ & $(0.334)$ & $(0.369)$ \\
\hline \multirow[t]{2}{*}{ Age-squared } & $-0.909^{*}$ & $-1.282^{* * *}$ & $-0.945^{*}$ \\
\hline & $(0.516)$ & $(0.479)$ & $(0.544)$ \\
\hline \multicolumn{4}{|l|}{ Education (ref: high school) } \\
\hline \multirow[t]{2}{*}{ Technical college/vocational school } & -0.043 & -0.079 & -0.243 \\
\hline & $(0.329)$ & $(0.326)$ & $(0.567)$ \\
\hline \multirow[t]{2}{*}{ Two-year college } & -0.501 & -0.533 & $0.865^{* *}$ \\
\hline & $(0.378)$ & $(0.371)$ & $(0.350)$ \\
\hline \multirow[t]{2}{*}{ Four-year college or above } & -0.510 & -0.472 & $1.448^{* * *}$ \\
\hline & $(0.386)$ & $(0.371)$ & $(0.385)$ \\
\hline \multicolumn{4}{|l|}{ Employment status (ref: not employed) } \\
\hline \multirow[t]{2}{*}{ Employed part time } & $-0.655^{* *}$ & $-0.670^{* *}$ & $-1.254^{* * *}$ \\
\hline & $(0.301)$ & $(0.295)$ & $(0.368)$ \\
\hline \multirow[t]{2}{*}{ Employed full time } & $-0.713^{* *}$ & $-0.734^{* * *}$ & $-0.606^{*}$ \\
\hline & $(0.285)$ & $(0.283)$ & $(0.350)$ \\
\hline \multirow[t]{2}{*}{ Husband's labor income } & -0.023 & -0.038 & -0.005 \\
\hline & $(0.055)$ & $(0.056)$ & $(0.042)$ \\
\hline Wald tests & & $2.87^{* *}$ & \\
\hline [p-value $]$ & & [0.045] & \\
\hline Log-likelihood & -262.63 & -283.76 & -198.90 \\
\hline Pseudo $R^{2}$ & 0.088 & 0.121 & 0.104 \\
\hline Observations & 3,537 & 3,537 & 901 \\
\hline
\end{tabular}

Notes: House value specification is change in rate. Robust standard errors clustered by household ID are in parentheses. Dummy variables for the number of existing children, region, city size, and survey year are included but results are not shown. The baseline hazard is stratified by birth cohort and the year moved into current residence. Age-squared divided by 100 . Predicted house value changes (for each region-city size-year combination) are from estimation results in Table 6. Estimation sample is existing homeowners for results in models [1] and [2] and renters for results in model [3]. The null hypothesis of $\beta_{G}=\beta_{L}$ is tested using one-sided Wald tests against the alternative of $\beta_{G}<\beta_{L}$. The test statistics have a chi-squared distribution with one degree of freedom. ${ }^{* * *},{ }^{* *}$, and ${ }^{*}$ indicate significance at the $0.01,0.05$, and 0.10 levels, respectively. 


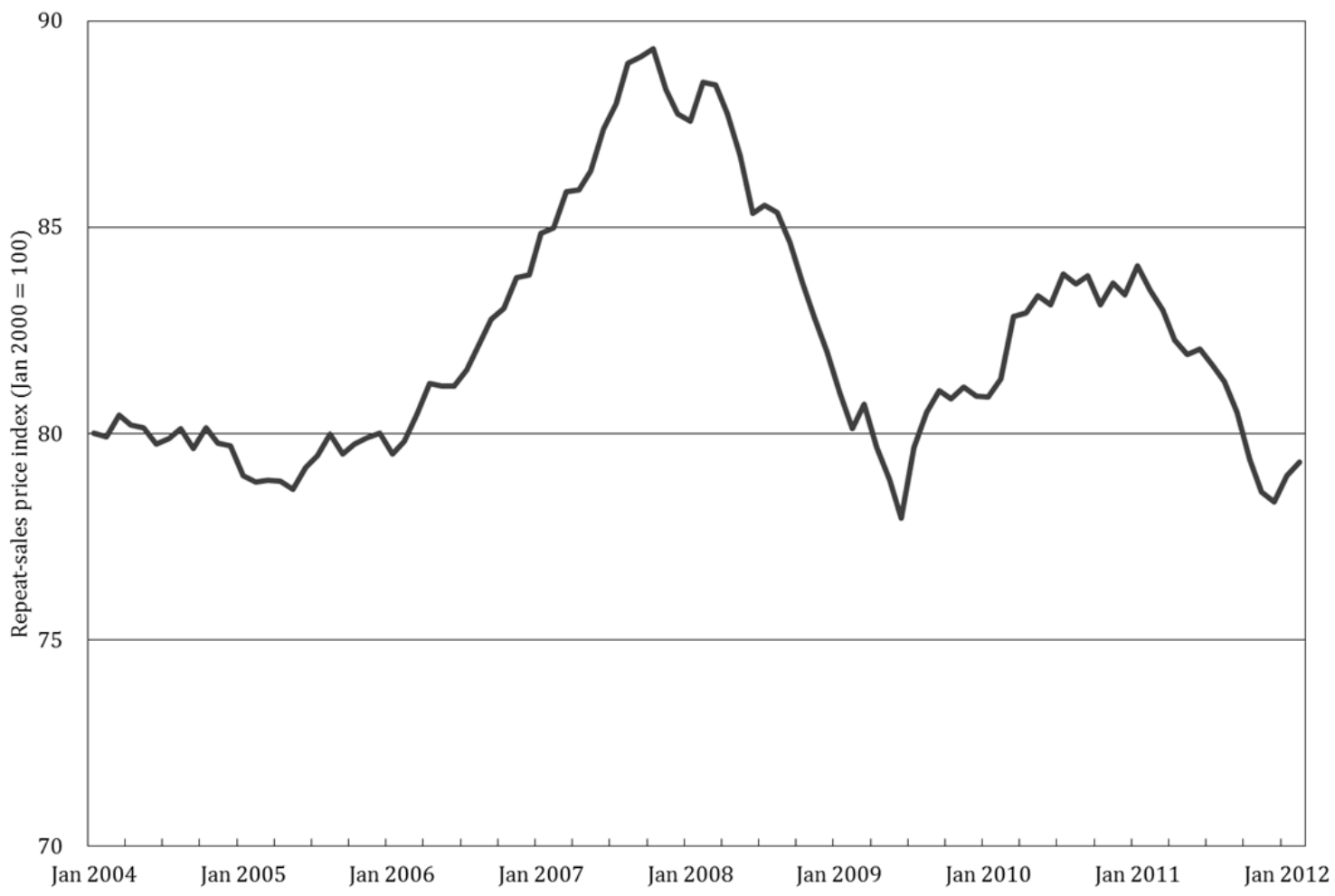

Source: Japan Real Estate Institute

Fig. 1: Repeat-sales price index for the Tokyo metropolitan area 


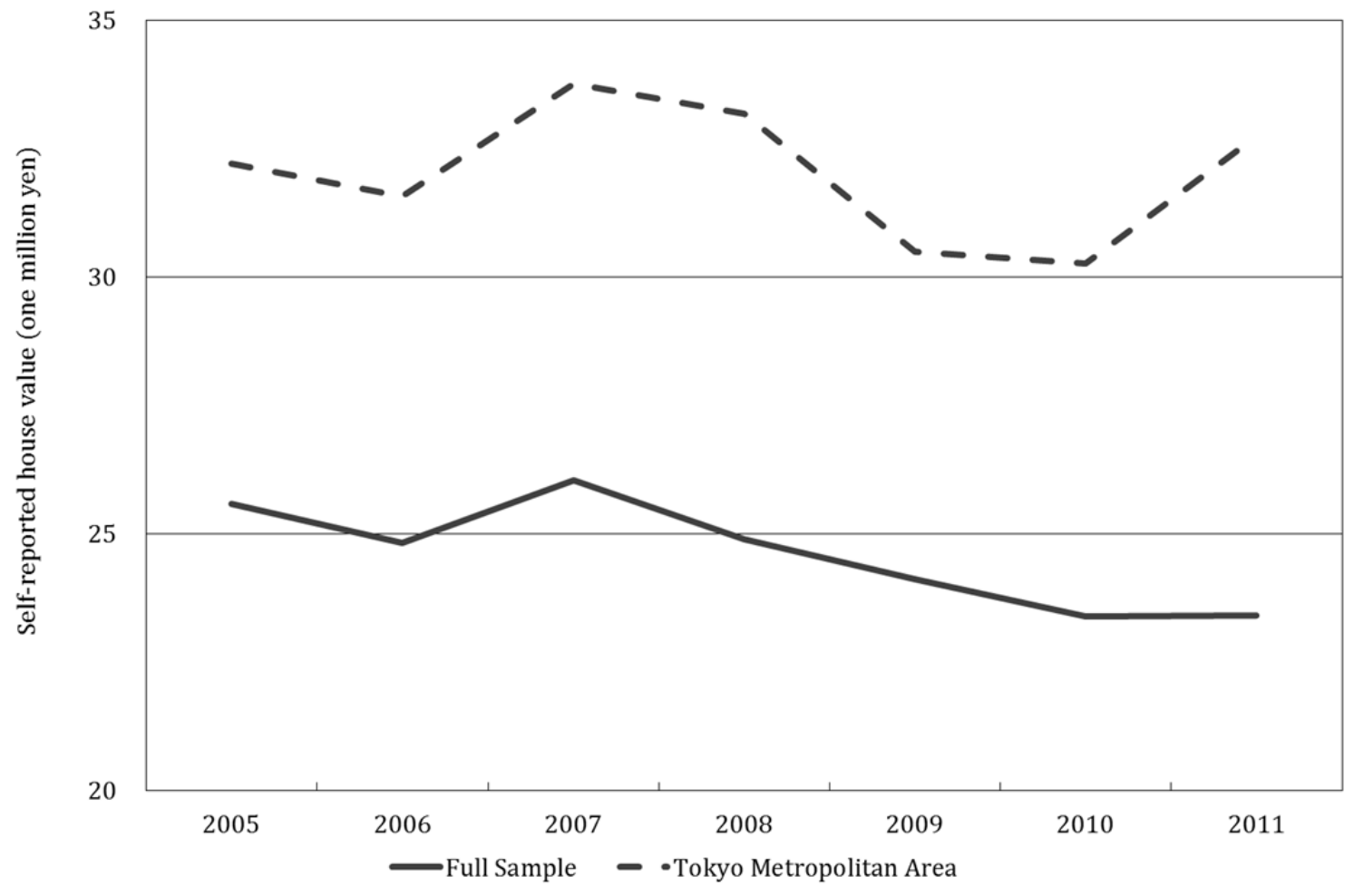

Source: Keio Household Panel Survey

Fig. 2: Average self-reported home values 